\title{
Effect of streptozotocin-induced diabetes on the autonomic ganglia of albino rats
}

\author{
Muhamed Faizal, Aijaz Ahmed Khan \\ Department of Anatomy, Jawaharlal Nebru Medical College, Aligarb Muslim University, Aligarh, U.P, India
}

\begin{abstract}
Objectives: One of the common clinical observations regarding long-standing hyperglycemia is autonomic neuropathy, probably due to its unfavorable destructive effects on the neurons of the autonomic ganglia. Accordingly, the current study was aimed to analyze the effect of experimental hyperglycemia on parasympathetic pterygopalatine ganglion (PtG) and sympathetic coeliac ganglion $(\mathrm{ClG})$ of albino rats.

Methods: Thirty-six albino rats were divided into six groups ( $n=6$, each) and were designated as control, two weeks, one month, two months, four months and six months groups. Diabetes was induced with a single dose of streptozotocin (STZ, $60 \mathrm{mg} / \mathrm{kg}$, i.p.). Body weight and blood sugar were monitored at biweekly intervals. At the end of each experimental period, animals were euthanized by deep ether anesthesia and blood samples were collected by direct puncture of heart for biochemical analysis. Animals were perfused with Karnovsky fixative. After 48 hours, tissue samples were collected and processed for light microscopy.

Results: Biochemical analysis of serum revealed increased serum creatinine and reduced serum total protein. Histopathology and histomorphometry of ganglia revealed that the progressively increasing duration of hyperglycemia was associated with decreased proportion of small-sized neurons, increased proportion of large-sized neurons, dark and dead neurons, and thickening of capsular and endoneurial collagen.

Conclusion: The association of the long-standing hyperglycemia with increased neuronal death, altered proportion of neurons and deposition of collagen fibers in autonomic ganglia appear to be important contributing factors likely to be responsible for diabetic autonomic neuropathy.
\end{abstract}

Keywords: autonomic ganglia; collagen; diabetes; neuropathy; streptozotocin induced

Anatomy 2017;11(2):51-60 @2017 Turkish Society of Anatomy and Clinical Anatomy (TSACA)

\section{Introduction}

Diabetes mellitus is a group of common metabolic disorders that is characterized by hyperglycemia and insufficiency in production or action of insulin. ${ }^{[1]}$ Hyperglycemia is believed to be associated with increased free radicals and cellular oxidative stress, which initiates cellular injury leading to diabetic complications including retinopathy, neuropathy, nephropathy and coronary artery diseases. ${ }^{[2]}$ Hyperglycemia followed by high neuronal glucose levels leads to glucose neurotoxicity, ${ }^{[3]}$ and prolonged high intracellular glucose in neurons leads to a variety of functional and structural disorders in various region of nervous system. ${ }^{[4]}$ Due to high cytosolic oxidative stress, both sympathetic and parasympathetic neurons may be more suscepti- ble to pathological changes of oxidative stress like those in diabetes. ${ }^{[5]}$ Oxidative stress followed by mitochondrial dysfunction initiates neuronal apoptosis ${ }^{[6]}$ and is a major mediator of neurodegeneration in diabetes. ${ }^{[7]}$ Autonomic dysfunction affects normal functioning of the cardiovascular, respiratory, gastrointestinal, genitourinary, thermoregulatory, and neuroendocrine systems. ${ }^{[8]}$

Autonomic ganglia serve as the final output of discrete CNS structures that control the function of the periphery. ${ }^{[5]}$ The pterygopalatine ganglion $(\mathrm{PtG})$ is the largest parasympathetic ganglion located in the pterygopalatine fossa and is functionally attached to the facial nerve. Sensory fibers from the maxillary branch of trigeminal nerve and sympathetic fibers pass through ganglia, but do not synapse in them. ${ }^{[9]}$ The coeliac ganglia $(\mathrm{ClG})$ are a 
well-defined prevertebral sympathetic ganglia located on the sides of the coeliac trunk having a varying number of neurons with extensive dendritic fields. ${ }^{[10]} \mathrm{ClG}$ receive convergent synaptic input from spinal preganglionic neurons and peripheral intestinofugal neurons projecting from the gut. ${ }^{[11]}$ Related studies ${ }^{[1,13]}$ found changes in neurons and alteration of myelinated and unmyelinated nerve fibers and collagen without using any special stain. Therefore, the present study aimed at demonstrating these and possibly other changes in the arrangement of collagen fibers and neuronal structure by using special stainings for collagen, picrosirius red (PSR) and cresyl violet (CV) stainings together with histopathological, histomorphological and biochemical parameters, in experimentally induced diabetic rats after two weeks to six months periods.

\section{Materials and Methods}

After approval from Institutional Animal Ethics Committee (No: 9025/2014), 36 albino rats of either sex weighing approximately $250 \mathrm{~g}$ were obtained from central animal house, Aligarh Muslim University, Aligarh were used for the present study. Prior to commencement of the experiments, all animals were placed to the new environmental condition for a period of one week. Animals were kept in a well-ventilated room and were supplied standard pellet diet and water ad libitum and maintained on a $12 / 12 \mathrm{~h}$ light/dark cycle.

Animals were divided into following six groups having six rats in each group: Group 1: non-diabetic healthy control, age-matched; diabetic experimental groups: Group 2: two week, Group 3: one month; Group 4: two months; Group 5: four months; Group 6: six months.

The experimental diabetic model was induced using streptozotocin (STZ) $(60 \mathrm{mg} / \mathrm{kg}$, aquous sol., I.P., only once; SRL-Sisco Research Laboratories, Mumbai, India) after 12 hours of fasting. Blood sugar level was monitored with a glucometer from the blood obtained from the lateral tail vein before and on the 2nd day of streptozotocin injection. Animals with blood sugar level 250 $\mathrm{mg} / \mathrm{dl}$ and above were considered as diabetic. Both body weight and blood glucose levels of all animals in each group were monitored biweekly. ${ }^{[14]}$

After the designated period, all experimental and agematched control rats were euthanized with overdose of ether general anesthesia, and the rats were perfusionfixed with Karnovsky's fixative.

PtGs were carefully dissected out from the pterygopalatine fossa along with the maxillary branch of the trigeminal ganglion and the $\mathrm{ClG}$ from either sides of the celiac trunk were secured en bloc. Both tissues were processed for paraffin embedding. $5 \mu \mathrm{m}$ thick sections were stained with Hematoxyline and Eosin (H\&E), cresyl $\mathrm{CV}$ and PSR. Only H\&E and CV stained sections were used for measuring the neuronal diameter. Random photomicrographs were recorded under $\times 400$ magnification of trinocular microscope (Olympus, BX40, Tokyo, Japan) by digital camera (Sony 18.2 MP, Tokyo, Japan) and measurements were made by using software Motic Images Plus version 2.0 (Motic, Kowloon, Hong Kong) ${ }^{[14]}$ Sufficient numbers of random images from both sides of $\mathrm{PtG}$ and ClG were taken in order to get 1000 neurons having a clear nucleus with one or more nucleoli to be used for the histomorphometry. Based on their diameter, neurons were divided into small $(<20 \mu \mathrm{m})$, medium (20-30 $\mu \mathrm{m})$ and large sized $(>30 \mu \mathrm{m})$. Proportions of different size of neurons in randomly selected 1000 neurons were calculated in each group. The neurons were also identified as dark or light on the basis of their morphology and staining characteristics of cell body and nucleus with visible nucleolus.

Blood glucose levels were measured from the lateral tail vein blood at biweekly intervals with a glucometer. At the end of each study period, blood samples were obtained from direct puncture of heart and collected into sterilized plastic vials. Samples were allowed to clot, centrifuged at $2500 \mathrm{rpm}$ for 30 minutes. The serum was separated and stored in sterile plastic vials and assayed for serum total protein content and serum creatinine level by using Avantor BeneSpheraTM Clinical Chemistry Analyzer C61 (Avantor Performance Materials, Inc., Center Valley, PA, USA).

The number of neurons, serum total protein and serum creatinine levels were statistically analyzed using one-way ANOVA followed by Tukey's test. All numerical values were expressed as Mean \pm SD and $p<005$ was considered as statistically significant.

\section{Results}

Consistent with the known effects of induced hyperglycemia, the STZ-treated rats displayed classical clinical symptoms of diabetes such as polydipsia, polyuria and polyphagia. The mean body weights of all diabetic groups were reduced compared to the control group during experimental period as reported earlier. ${ }^{[14]}$ The changes observed between $2 \mathrm{~W}$ diabetic and age-matched control group were statistically not significant $(>0.05)$, but they were significantly $(\mathrm{p}<0.05)$ reduced at all stages of the induced diabetes compared to age-matched controls. Rise of blood sugar level was observed above 500 $\mathrm{mg} / \mathrm{dl}$ after 48 hours of induction in diabetic groups which remained so throughout experimental period. 
Table 1

Serum total protein and creatinine levels in diabetic groups compared to age-matched controls.

\begin{tabular}{lcccccc}
\hline Parameter & Group & $\mathbf{2 W}$ & $\mathbf{1 M}$ & $\mathbf{2 M}$ & $\mathbf{4 M}$ & $\mathbf{6 M}$ \\
\hline Serum total protein $(\mathrm{g} / \mathrm{d} \mathbf{l})$ & Control & $5.97 \pm 0.04^{*}$ & $5.95 \pm 0.05^{*}$ & $5.99 \pm 0.03^{*}$ & $6.01 \pm 0.01^{*}$ & $5.98 \pm 0.05^{*}$ \\
& Diabetic & $5.23 \pm 0.01$ & $5.12 \pm 0.03$ & $5.00 \pm 0.07$ & $4.05 \pm 0.03$ & $3.96 \pm 0.04$ \\
\hline Serum creatinine $(\mathrm{mg} / \mathrm{dl})$ & Control & $0.43 \pm 0.02$ & $0.42 \pm 0.06^{*}$ & $0.45 \pm 0.05^{*}$ & $0.44 \pm 0.07^{*}$ & $0.43 \pm 0.04^{*}$ \\
& Diabetic & $0.45 \pm 0.07$ & $0.63 \pm 0.08$ & $0.78 \pm 0.03$ & $0.93 \pm 0.09$ & $1.06 \pm 0.05$ \\
\hline
\end{tabular}

${ }^{*} \mathrm{p}<0.05$

After $2 \mathrm{~W}$, a significant difference $(\mathrm{p}<0.01)$ was observed when comparison was made between $2 \mathrm{~W}, 1 \mathrm{M}, 2 \mathrm{M}, 4 \mathrm{M}$, and $6 \mathrm{M}$ diabetic rats to age-matched controls and corresponding diabetic group rats, respectively (Table 1).

\section{Microscopic observations}

The PtG was located in the pterygopalatine fossa closely related with maxillary division of trigeminal nerve. Neurons in $\mathrm{PtG}$ were closely packed with homogenous distribution. Most neurons appeared round to oval in shape and almost all neurons were in the range of small to medium size with cell body diameter of 15 to $30 \mathrm{Im}$. Each neuron was surrounded by a thin capsule of small satellite cells with delicate connective tissue and unmyelinated nerve fibers between them. Fibrocytes and occasional intraganglionic blood capillaries were also noticed. Each ganglion had its own protective connective tissue capsule. Neuronal cell bodies were characterized by oval large euchromatic nuclei. In control, $2 \mathrm{~W}$ and $1 \mathrm{M}$ diabetic groups, Nissl substance was coarser and sparse in the perikaryal area. However in $2 \mathrm{M}, 4 \mathrm{M}$ and $6 \mathrm{M}$ diabetic groups, most of the parasympathetic neurons had peripheral condensed rim of Nissl substance. Most of the literature suggest that nuclei of a sensory ganglion neurons are located centrally ${ }^{[14]}$ and those in the autonomic ganglia are located eccentrically. ${ }^{[15]}$ However, in the current study, we observed that the nucleus appeared to be located centrally in most of the PtG neurons. Similarly, the common text book description is that the autonomic ganglion neurons are multipolar ${ }^{[15]}$ but in the present study quite many of the neurons in both PtG and $\mathrm{ClG}$ had appearance very much similar to typical sensory ganglion neurons. Interestingly, all nuclei had a single and large densely stained eccentrically placed nucleolus. (Figures $\mathbf{1}$ and $\mathbf{2}$ ). Collagen fibers were observed in the perineuronal capsule. The unmyelinated nerve fibers and connective tissue fibers were also seen between the neurons. The control and $2 \mathrm{~W}$ diabetic groups were associated with fewer collagen fibers around the neurons and along the nerve fibers, but in other groups progressively thickened collagen fibers in the periganglionic capsule, perineuronal capsule and also along the nerve bundles were noticed. Perineuronal spaces were commonly noticed in $1 \mathrm{M}, 2 \mathrm{M}, 4 \mathrm{M}$, and $6 \mathrm{M}$ diabetic groups (Figure 3).

In cresyl violet-stained sections of the celiac ganglion, both control and diabetic groups showed the same basic cellular architecture, consisting of a moderately dense arrangement of sympathetic neurons separated by bundles of unmyelinated nerve fibers and surrounded by well-
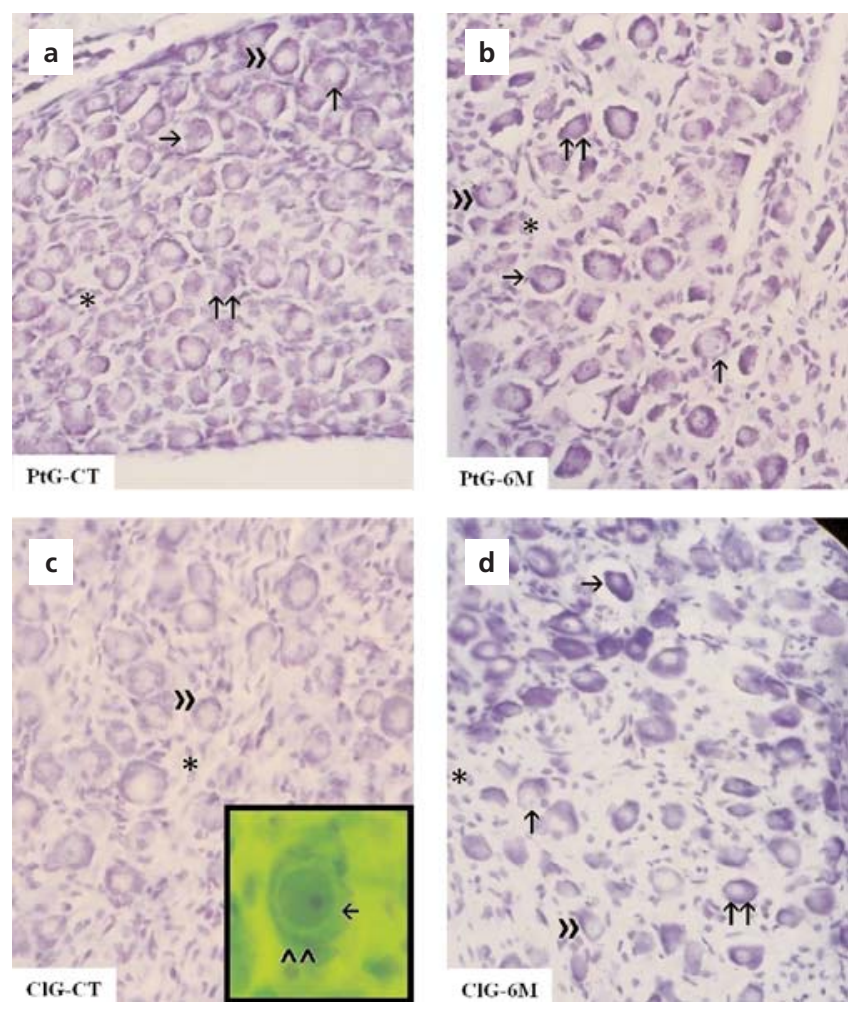

Figure 1. (a-d) Photomicrographs from rat autonomic ganglia showing neuron having peripheral ring $(\uparrow \uparrow)$, eccentric nucleus $(\uparrow)$, eccentric nucleolus (»), dark neuron $(\rightarrow)$ and fibrocytes (*) (Cresyl violet stain, $\times 400)$. Inset showing moderate yellow fluorescence in perikarya occupied by fine Niss granules $(\leftarrow)$ and no fluorescence in the peripheral rim $(\wedge \wedge)$ (PSR stain, $\times 1000$ ). [Color figure can be viewed in the online issue, which is available at www.anatomy.org.tr] 
defined collagen fibers around the neurons and along the nerve fibers and ganglionic capsule. Most of the neuronal cell bodies inside the ClG had eccentrically placed, large, euchromatic nuclei having deeply stained nucleoli (Figures 1-3) which were also located eccentrically. Fine Nissl granules were distributed uniformly throughout the cytoplasm. Lipofuscin pigments were not obviously seen in both control and experimental groups. All ganglion neurons in the control group were covered by thin sheath of fewer sparsely located satellite glial cells. In prolonged diabetic groups, the satellite cells were less organized as compared to age-matched control groups (Figures $\mathbf{1}$ and 2). Though collagen fibers were present in variable amounts in the perineuronal capsules, nerve fascicles and periganglionic capsules. The overall amount of collagen and thickness of their fibers revealed direct correlation with the increasing duration of hyperglycemic state as compared to the age-matched controls. Perineuronal spaces were found in the $6 \mathrm{M}$ diabetic group. Intraganglionic blood capillaries were more often seen close to the neurons in diabetic groups (Figure 4). The $2 \mathrm{~W}$ diabetic group revealed two medium sized neurons housed within the same perineuronal sheath as suggested by the absence of satellite cells and fibrous capsule between them (Figure 4).
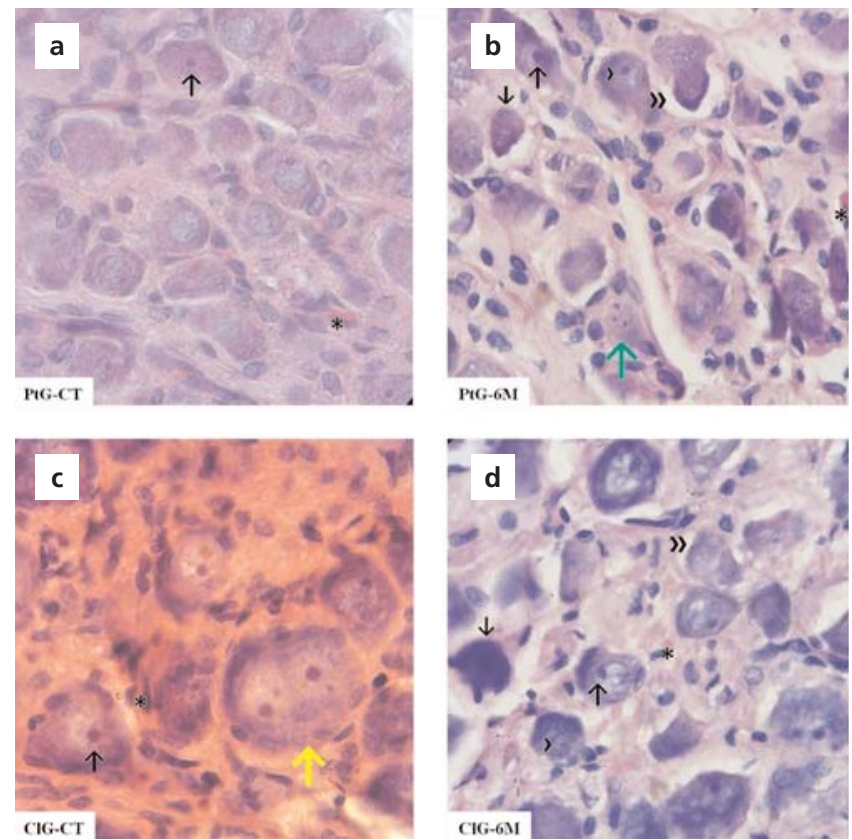

Figure 2. (a-d) Photomicrographs from rat autonomic ganglia showing eccentric nucleoli $(\uparrow)$ blood capillaries (*), dark neuron (»), dead neuron $(\downarrow)$ and perineuronal space $(*)$. Yellow arrow showing organized two $\mathrm{CIG}$ neurons enclosed in common perineuronal sheath and glial satellite cells. Connective tissue sheath is not visible between two cells. Green colored arrow showing CIG neuronal nucleus having three nucleoli (H\&E stain, $\times 1000$ ). [Color figure can be viewed in the online issue, which is available at www.anatomy.org.tr]
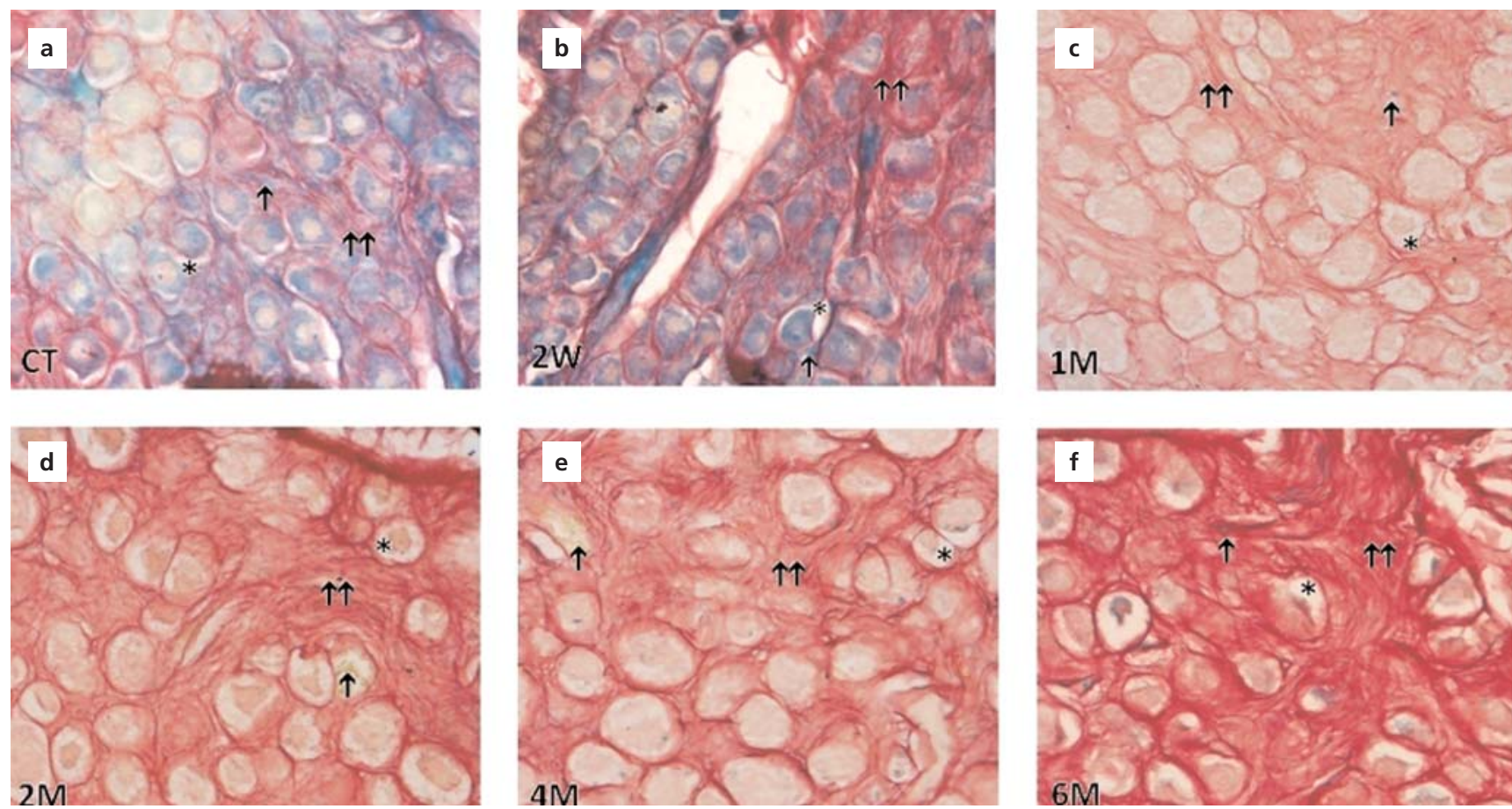

Figure 3. (a-f) Photomicrographs from rat PtG showing non-myelinated nerve fibers $(\uparrow \uparrow)$, blood capillaries $(\uparrow)$, and perineuronal space $(*)$. Note the prominence of collagen fibers (red colour) in $1 \mathrm{M}, 2 \mathrm{M}, 4 \mathrm{M}$ and $6 \mathrm{M}$ diabetic group (PSR with LFB stain, $\times 400$ ). [Color figure can be viewed in the online issue, which is available at www.anatomy.org.tr] 


\section{Histomorphometry}

In the PtG, the proportion of small sized neurons among 1000 neurons was significantly $(\mathrm{p}<0.05)$ decreased in $2 \mathrm{M}$, $4 \mathrm{M}$ and $6 \mathrm{M}$ groups and the proportions of medium sized neurons were significantly $(\mathrm{p}<0.05)$ increased in $2 \mathrm{M}, 4 \mathrm{M}$ and $6 \mathrm{M}$ diabetic groups as compared to the age-matched control groups (Figure 5).

In 1000 neurons of the $\mathrm{ClG}$ of all diabetic groups, the proportion of small sized neurons were significantly $(p<0.05)$ decreased. However, in the $2 \mathrm{~W}$ diabetic group such decrement remained statistically non-significant as compared to the age-matched control group. In ClG of $1 \mathrm{M}, 2 \mathrm{M}, 4 \mathrm{M}$ and $6 \mathrm{M}$ diabetic groups, the proportion of medium and large sized neurons were significantly $(\mathrm{p}<0.05)$ increased as compared to the age-matched control group. In the $2 \mathrm{~W}$ diabetic group, the proportions of the total number of medium and large sized neurons were less compared to the age-matched control group, but not at a statistically significant level (Figure 6).

\section{Biochemical analysis}

In all diabetic groups, the serum total protein levels were significantly $(\mathrm{p}<0.05)$ decreased compared to age-matched
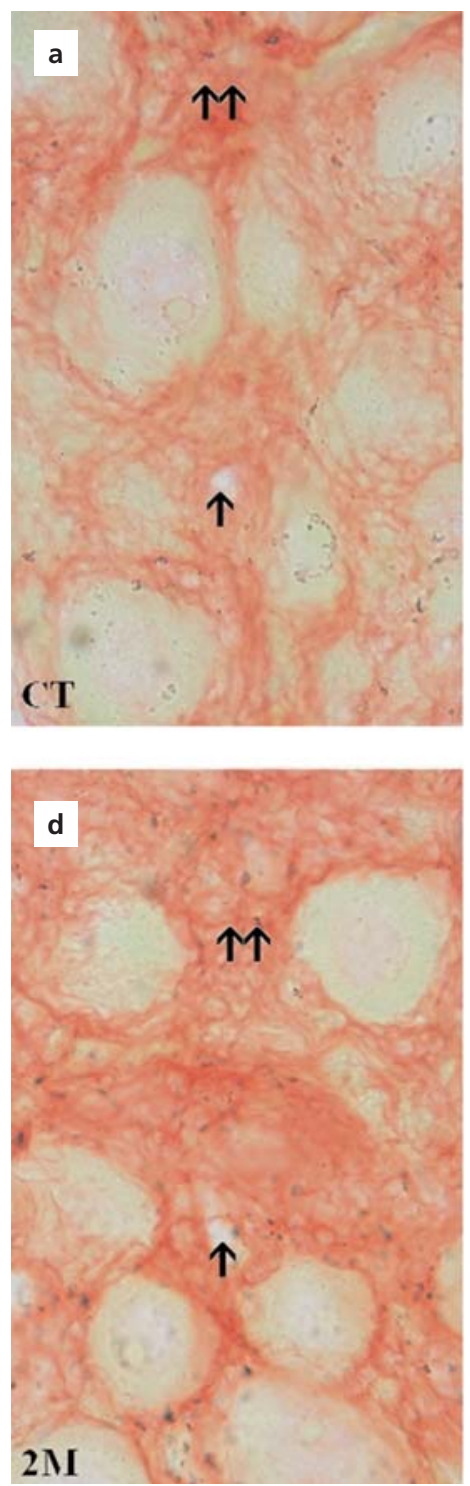
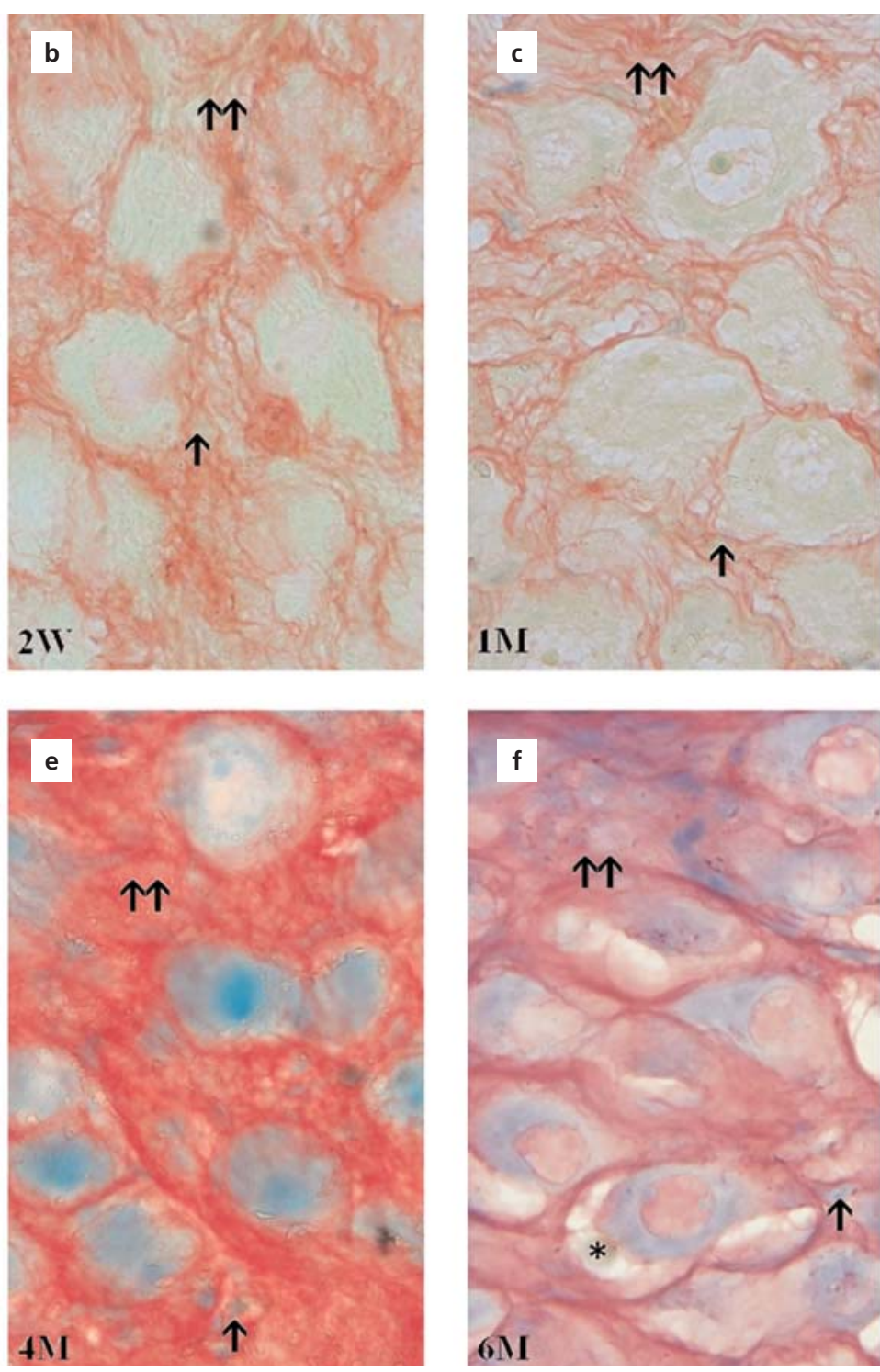

Figure 4. (a-f) Photomicrographs from rat CIG showing non-myelinated nerve fibers $(\uparrow \uparrow)$, blood capillaries $(\uparrow)$, and perineuronal space $\left(^{*}\right)$. Note the prominence of collagen fibers (red colour) in $2 \mathrm{M}, 4 \mathrm{M}$ and $6 \mathrm{M}$ diabetic groups (PSR with LFB stain, $\mathrm{x} 1000$ ). [Color figure can be viewed in the online issue, which is available at www.anatomy.org.tr] 


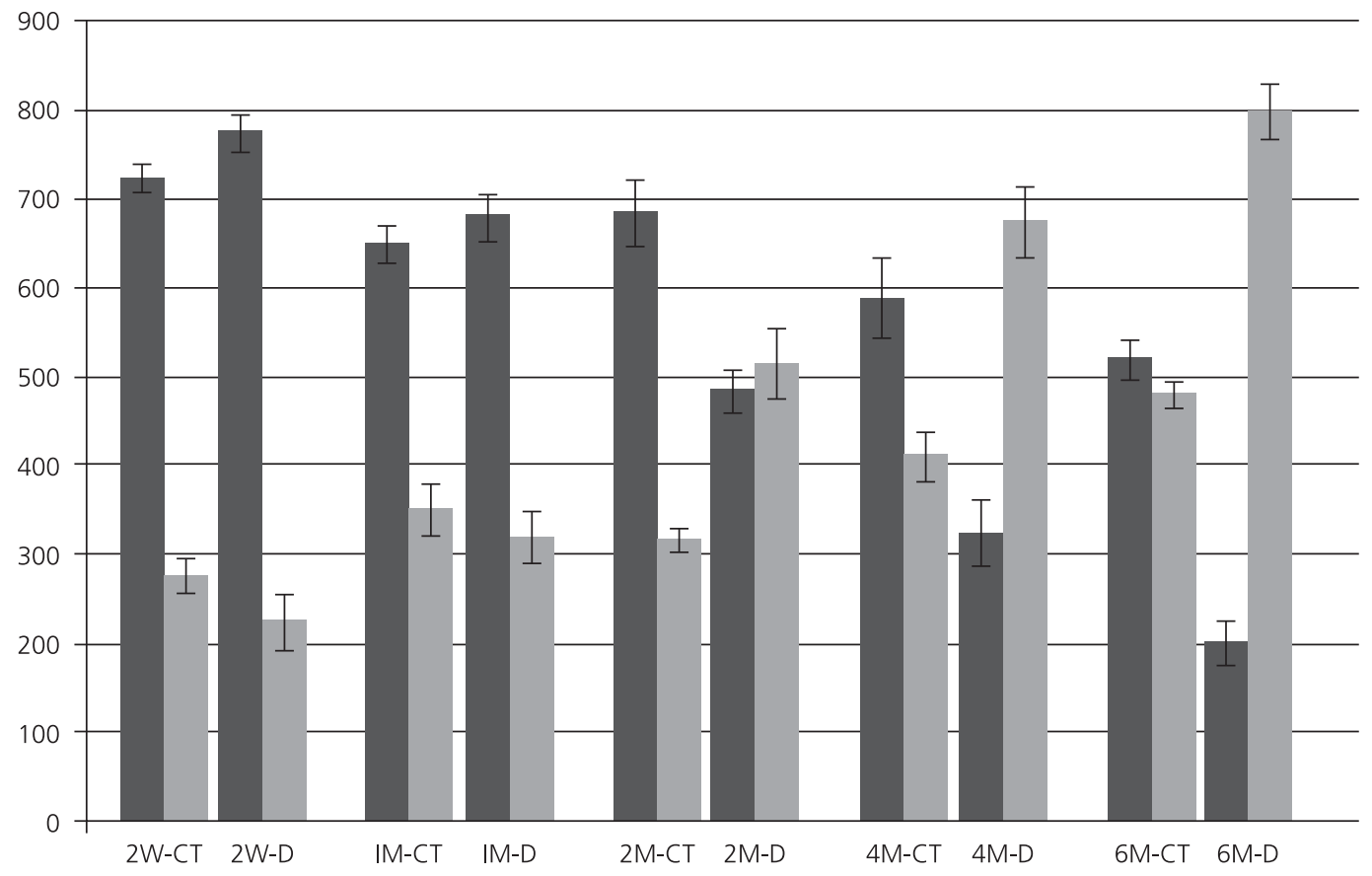

Figure 5. The proportion of small sized neurons was significantly $(p<0.05)$ reduced in all diabetic groups, while that of medium sized neurons significantly $(p<0.05)$ increased in all diabetic groups except $2 \mathrm{~W}$ and $1 \mathrm{M}$ compared to age-matched control groups.

control groups, while serum creatinine levels were significantly $(\mathrm{p}<0.05)$ increased in all diabetic groups except $2 \mathrm{~W}$, as compared to age-matched control groups. In $2 \mathrm{~W}$ diabetic group, the serum creatinine levels were less compared to the age-matched control group, but not at significant level ( $>0.05)$ (Table 1).

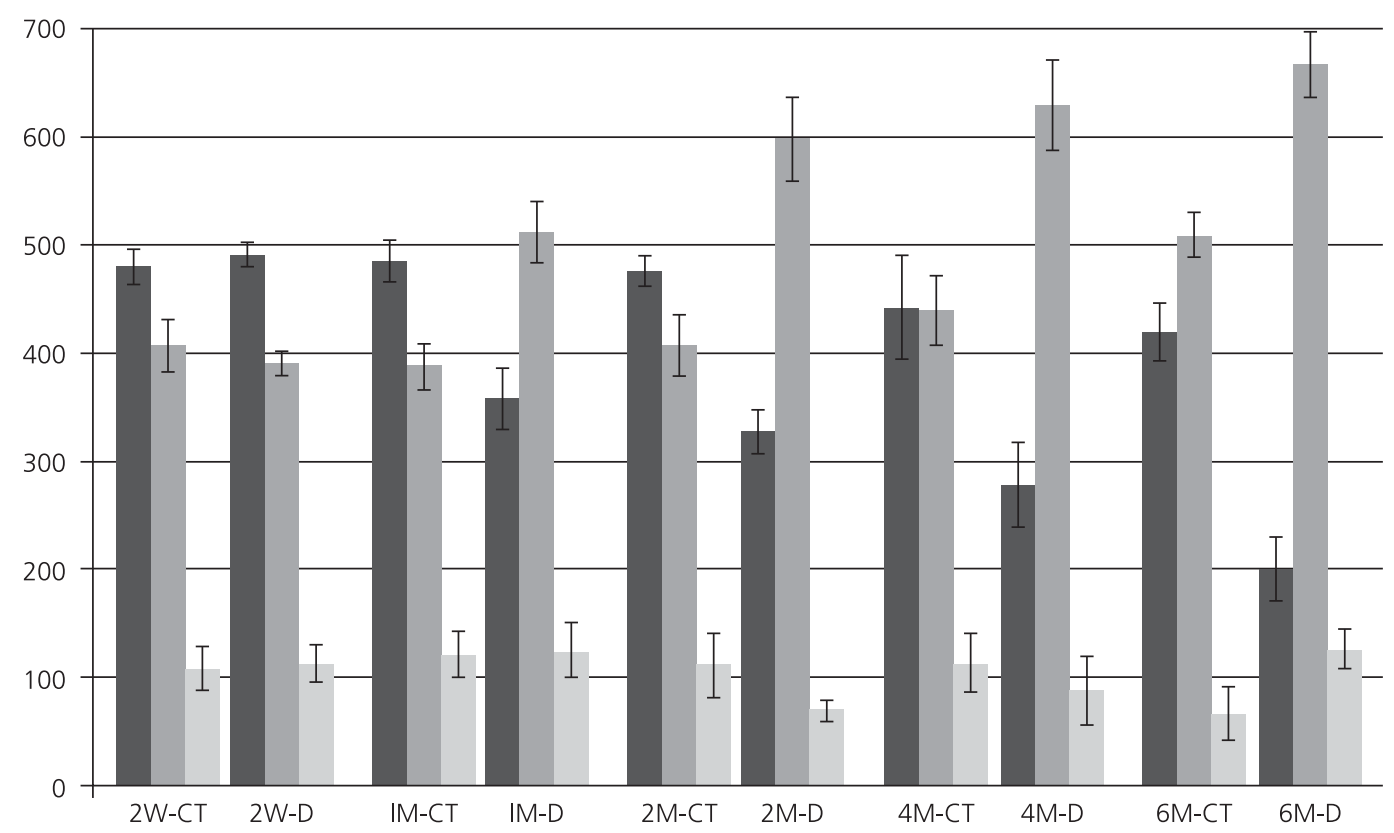

Figure 6. The proportion of small sized neurons in CIG was significantly $(p<0.05)$ reduced in all diabetic groups except $2 \mathrm{~W}$ group, while the total number of the medium and large sized neurons significantly $(p<0.05)$ increased in all diabetic groups except $2 \mathrm{~W}$ compared to age-matched control groups. 


\section{Discussion}

Diabetes mellitus is a group of metabolic disorders of carbohydrate, fat and protein metabolism characterized by low grade inflammatory metabolic disorder ${ }^{[16,17]}$ in which a person has high blood sugar, either characterized by insufficient amounts of insulin or because cells do not respond to the insulin that is produced, which leads to hyperglycemia. ${ }^{[18]}$ Reduced anabolic insulin hormone in DM, promotes protein catabolism and releasing amino acids for gluconeogenesis ${ }^{[19]}$ which leads to increased muscle wasting due to loss of tissue proteins and reduction of body weight. ${ }^{[20]}$ In the current study, all diabetic groups maintained the hyperglycemic state throughout the experimental period and showed progressive reduction in body weight in the STZ-induced rats, reflecting an increase in protein catabolism and loss of tissue proteins. This result is in agreement with previous related studies. ${ }^{[21-23]}$

In this study, structure of both sympathetic and parasympathetic autonomic ganglia and orientation of nerve fibers in both control and experimental groups were, in general, found to be similar to those reported earlier. ${ }^{[10,24-26]}$ Each neuron in $\mathrm{ClG}$ is anatomically and functionally independent. In the present study, a couple of neurons appeared to share a common sheath formed by satellite glial cells and the interneuronal sheath connective tissue was not visible. Significance of such intimate association between certain neurons remains unclear. On one hand, absence of the interneuronal sheath element makes its appearance very akin to a binucleate neuron; similar findings were observed in another study on the trigeminal ganglion. ${ }^{[27]}$

The present study demonstrates a concomitant increase in the thickness of collagen fibers located in the capsule of the ganglia, perineuronal capsule and interfascicular region of $\mathrm{PtG}$ and $\mathrm{ClG}$. Previous studies showed progression of fibrosis in a diabetic heart by PKC- $\beta$, p38 mitogen activated protein kinase expression in redox reaction, ${ }^{[28]}$ and AGE and RAGE interaction increased expression of TGF- $\beta$ and contributed to the development of submesothelial fibrosis and neoangiogenesis. ${ }^{[29]}$ In the current study, in PSR and CV stained sections, control and $2 \mathrm{~W}$ diabetic groups of $\mathrm{PtG}$, and control, $2 \mathrm{~W}$, and $1 \mathrm{M}$ diabetic groups of $\mathrm{ClG}$ revealed thin collagen fibers around the neurons and along the nerve bundles; however, in $1 \mathrm{M}$ and $2 \mathrm{M}$ diabetic groups of $\mathrm{PtG}$ and in the $2 \mathrm{M}$ diabetic group of $\mathrm{ClG}$, the collagen fibers were of moderate thickness. However, in $4 \mathrm{M}$ and $6 \mathrm{M}$ diabetic groups, both $\mathrm{PtG}$ and $\mathrm{ClG}$ revealed a remarkable thickening of collagen in the capsule of the $\mathrm{ClG}$ ganglia, perineuronal capsule, interfascicular region, and endoneurium. Comparison of these with previous observations reported earlier ${ }^{[14,30]}$ indicate that hyperglycemia seems to accelerate fibrosis in terms of the amount and thickness of collagen fibers. In earlier studies on sensory ganglia, the perineuronal spaces in some of the neurons were suggested to be due to either shrinkage or apoptosis of neurons with the progression of hyperglycemia. ${ }^{[1,30]}$ In the present study, similar observations were found in $1 \mathrm{M}, 2 \mathrm{M}, 4 \mathrm{M}$ and $6 \mathrm{M}$ diabetic groups of $\mathrm{PtG}$ and $6 \mathrm{M}$ diabetic group of $\mathrm{ClG}$.

The dark neurons are also considered as apoptotic type neurons or a type of cell degeneration with hyperelectron density properties and hyperbasophilia. ${ }^{[1-33]}$ Many researchers consider neuronal cell death mainly due to apoptotic changes. ${ }^{[34]}$ In the present study, it was observed that, on the progression of the duration of hyperglycemic state in both PtG and $\mathrm{ClG}$, the number of dark neurons increased in agreement with earlier studies showing that hyperglycemia and increased free radical generation in diabetes accelerated the formation of dark neurons. ${ }^{[3]}$ The number of neurons with a distinct peripheral rim of Nissl substance also seems to increase with the duration of hyperglycemia which may be secondary to chromatolytic changes. ${ }^{[35,36]}$

It is generally accepted that the PtG contains both vasomotor and secretomotor neurons ${ }^{[37]}$ and that they are independent of each other. ${ }^{[38]}$ In the present study, were observed both small and medium sized neurons in control and experimental groups. In another study on the otic ganglion of the cat, small and large sized neurons were described as vasomotor and secretomotor, mainly involved with blood vessel vasomotor activity and glandular secretion of the salivary gland. ${ }^{[39]}$ In our study, there is evidence for a minor change in neuronal proportion in the parasympathetic ganglia of diabetic rats. The proportion of small sized neurons in PtG significantly $(\mathrm{p}<0.05)$ decreased in all diabetic groups. Therefore, these findings indicate that in diabetes the isolated asymptomatic progressive involvement of lacrimal secretion in progression of hyperglycemia. The impaired tear secretion in prolonged hyperglycemic state which is commonly believed to be due to age-dependent decline in glandular function and excessive fibrosis ${ }^{[0,41]}$ may also be partly attributed to the loss of small sized neurons of PtG observed in the present study.

$\mathrm{ClG}$ is the part of sympathetic ganglia located near the celiac trunk, a complex relay and integrative center for projections from the parasympathetic, sensory, spinal cord-derived motor, and retrograde intestinofugal sources. ${ }^{[42]}$ Most neurons are noradrenergic and supply the stomach, spleen, pancreas, small intestine and mesen- 
teric blood vessels. ${ }^{[43]}$ In the current study, we identified small, medium and large sized neurons. Such neuronal population has earlier been functionally divided into pilomotor, vasomotor and secretomotor neurons. ${ }^{[4]}$ In our study, there is evidence for a minor change in neuronal proportion in the $\mathrm{ClG}$. It was noticed that the proportion of small sized neurons in $\mathrm{ClG}$ were significantly $(\mathrm{p}<0.05)$ decreased, however medium and large sized neuron were significantly $(\mathrm{p}<0.05)$ increased in $1 \mathrm{M}, 2 \mathrm{M}, 4 \mathrm{M}$ and $6 \mathrm{M}$ diabetic groups. Therefore, these findings indicate that diabetes leads to progressive dysregulation of the sympathetic control of motility in the stomach and small intestine, and of fluid exchange in the small intestine with progression of hyperglycemia probably due to altered function and or loss different neurons along with age-dependent decline in glandular function and excessive fibrosis. ${ }^{[41,45]}$

In the present study, dead neurons were easily differentiated due to their dark staining characteristics as compared to normal neurons in the control group. In $4 \mathrm{M}$ and $6 \mathrm{M}$ diabetic groups, the neurons with dark nuclei appeared shrunken, nuclear membranes became less distinct and nucleoplasm no more remained open-faced as similar to described earlier. ${ }^{[46]}$ However, with the progression of hyperglycemic state in diabetic groups, the number of dead neurons increased in agreement with an earlier study, ${ }^{[4]}$ suggesting diabetes enhances neuronal death.

Lipofuscin pigment (senile pigment) is described to be one of the typical features of the sympathetic ganglia and can be shown described by H\&E stain. ${ }^{[15]}$ In our present study, lipofuscin pigment could neither be located in the control nor in any experimental groups after using with different stains. Certain literature suggest that lipofuscin pigment shows auto- fluorescent property with blue light. ${ }^{[47]}$ Diabetes is said to accelerate accumulation of fluorescent granules in sensory ${ }^{[48]}$ and sympathetic neurons ${ }^{[49]}$ which could not be confirmed in the present study. However, the perikarya of $\mathrm{ClG}$ neurons showed a lowgrade yellow fluorescence in the region occupied by fine Nissl substance (Figure 1).

In this study, it has been shown that, as shown earlier, abnormally high levels of serum creatinine are consistent with impaired kidney function ${ }^{[50]}$ and the serum creatinine level increased in all diabetic groups parallel to the severity of hyperglycemia, but the serum total protein levels were reduced and altered in serum total protein relating the hyperglycemia to a low grade inflammatory process. ${ }^{[51]}$ Similar findings have been shown in the other related studies. ${ }^{[52,53]}$

\section{Conclusion}

Based on histopathological, histomorphological and biochemical findings, it is concluded that prolonged hyperglycemic state leads to increased serum creatinine level, reduced serum total protein and proportion of small sized neurons, increase in dark and dead neurons and thickening of collagen fibers in autonomic ganglia. Therefore, it appears that one of the important contributory factors in development of autonomic neuropathy in chronic diabetes might be the hyperglycemia-induced neuronal cytotoxicity and altered perineuronal microenvironment in terms of increased fibrosis within the autonomic ganglia.

\section{Acknowledgement}

The authors would like to gratefully acknowledge all kinds of support and co-operation received from Department of Anatomy and Neuroanatomy Laboratory, Jawaharlal Nehru Medical College, Aligarh Muslim University, Aligarh, India.

\section{References}

1. Maritim AC, Sanders RA, Watkins JB. Diabetes, oxidative stress, and antioxidants: a review. J Biochem Mol Toxicol 2003;17:24-38.

2. Phillips M, Cataneo RN, Cheema T, Greenberg J. Increased breath biomarker of oxidative stress in diabetes mellitus. Clin Chim Acta 2004;344:189-94.

3. Tomlinson DR, Gardiner NJ. Glucose neurotoxicity. Nat Rev Neurosci 2008;9:36-45.

4. Guven A, Yavuz O, Cam M, Comunoglu C, Sevinc O. Central nervous system complications of diabetes in streptozotocin-induced diabetic rats: a histopathological and immunohistochemical examination. Int J Neurosci 2009;119:1155-69.

5. Rudchenko A, Akude E, Cooper E. Synapses on sympathetic neurons and parasympathetic neurons differ in their vulnerability to diabetes. J Neurosci 2014;34:8865-74.

6. Srinivasan S, Stevens M, Wiley JW. Diabetic peripheral neuropathyevidence for apoptosis and associated mitochondrial dysfunction. Diabetes 2000;49:1932-8.

7. Fernyhough A, Chowdhury SKR, Schmidt RE. Mitochondrial stress and the pathogenesis of diabetic neuropathy. Expert Rev Endocrinol Metab 2010;5:39-49.

8. Vinik AI, Maser RE, Mitchell BD, Freeman R. Diabetic autonomic neuropathy. Diabetes Care 2003;26:1553-79.

9. Siessere S, Vitti M, de Sousa, LG, Semprini M, Iyomasa MM, Regalo SC. Anatomic variation of cranial parasympathetic ganglia. Braz Oral Res 2008;22:101-5.

10. Sisu AM, Petrescu CI, Cebzan CC, Motoc A, Bolintineanu S, vaida AM, Niculescu MC, Rusu MC. The adult coeliac ganglion: a morphologic study. Rom J Morphol Embryol 2008;49:491-4.

11. Sasahara TH, De souza RR, Machado MR, Da silva RA, Guidi WL, Ribeiro AA. Macro- and microstructural organization of the rabbit's celiac-mesenteric ganglion complex (Oryctolagus cuniculus). Ann Anat 2003;185:441-8. 
12. Schmidt RE, Dorsey DA, Beaudet LN, Frederick KE, Parvin CA, Plurad SB, Levisetti MG. Non-obese diabetic mice rapidly develop dramatic sympathetic neuritic dystrophy a new experimental model of diabetic autonomic neuropathy. Am J Pathol 2003;163: 2077-91.

13. Olsson Y, Sourander P. Changes in the sympathetic nervous system in diabetes mellitus. J Neurovisc Relat 1968;81:86-95.

14. Faizal PAM, Khan AA, Elsy B. Effect of experimental hyperglycemia on the trigeminal ganglia of albino rats. Int J Health Sci Res 2017;7: 191-8.

15. Young B, O'Dowd G, Woodford P. Wheater's functional histology: a text and colour atlas. 6th edition. Philadelphia (PA): Churchill Livingstone, 2016. 139 p.

16. Ernst MC, Sinal CJ. Chemerin at the crossroads of inflammation and obesity. Trends Endocrinol Metab 2010;21:660-7.

17. King KD, Jones JD, Warthen J. Microvascular and macrovascular complications of diabetes mellitus. Am J Pharm Educ 2005;69:1-10.

18. Cheng D. Prevalence, predisposition and prevention of type II diabetes. Nutr Metab (Lond) 2005;18:2-29.

19. Air EL, Strowski MZ, Benoit SC, Conarello SL, Salituro GM, Guan XM, Liu K, Woods SC, Zhang BB. Small molecule insulin mimetics reduce food intake and body weight and prevent development of obesity. Nat Med 2002;8:179-83.

20. Jain D, Bansal MK, Dalvi R, Upganlawar A, Somani R. Protective effect of diosmin against diabetic neuropathy in experimental rats. J Integr Med 2014;12:35-41.

21. Cintra LTA, Samuel RO, Prieto AK, Sumida DH, Dezan-Junior E, Gomes-Filho JE. Oral health, diabetes, and body weight. Arch Oral Biol 2017;73:94-9.

22. Elsy B, Maheshwari V, Khan AA. Effects of d alpha-tocopherol on progression of reepithelialization, matrix remodeling and appearance of epidermal appendages in secondary skin wounds of diabetic rats. Journal of Dermatology and Clinical Research 2016;4:1081.

23. Doddigarla Z, Ahmad J, Parwez I. Effect of chromium picolinate and melatonin either in single or in a combination in high carbohydrate diet?fed male Wistar rats. Biofactors 2016;42:106-14.

24. Elfvin LG. The ultrastructure of the superior cervical sympathetic ganglion of the cat: I. The structure of the ganglion cell processes as studied by serial sections. J Ultrastruct Res 1963;8:403-40.

25. Jurgaitiene R, Pauziene N, Azelis V, Zurauskas E. Morphometric study of age-related changes in the human intracardiac ganglia. Medicina (Kaunas) 2004;40:574-81.

26. Szczurkowski A, Kuder T, Nowak E, Kuchinka J. Morphology, topography and cytoarchitectonics of the pterygopalatine ganglion in Egyptian spiny mouse (Acomys cahirinus, Desmarest). Folia Morphol (Warsz) 2002;61:107-10.

27. Dilkash MNA, Ahmed SS, Khan AA. Comparative light microscopic study of trigeminal ganglion neurons in mammals. Curr Neurobiol 2010;1:25-9.

28. Adebiyi OA, Adebiyi OO, Owira PM. Naringin reduces hyperglycemia-induced cardiac fibrosis by relieving oxidative stress. PloS One 2016;11:1-15.

29. De Vriese AS, Flyvbjerg A, Mortier S, Tilton RG, Lameire NH. Inhibition of the interaction of AGE-RAGE prevents hyperglycemiainduced fibrosis of the peritoneal membrane. J Am Soc Nephrol 2003;14:2109-18.
30. Malak HW, Saleh SI, Salah El Din RA, Abdul Hamid HF. Histological and immunohistochemical study on the consequences of acute glycemic level alteration on the dorsal root ganglia and sciatic nerve integrity in neonatal albino rats. Egyptian Journal of Histology 2015;38:332-45.

31. Ahmadpour SH, Haghir H. Diabetes mellitus type 1 induces dark neuron formation in the dentate gyrus: a study by Gallyas' method and transmission electron microscopy. Rom J Morphol Embryol 2011;52:575-9.

32. Zsombok A, Toth Z, Gallyas F. Basophilia, acidophilia and argyrophilia of 'dark' (compacted) neurons during their formation, recovery or death in an otherwise undamaged environment. J Neurosci Methods 2005;142:145-52.

33. Krysko DV, Vanden Berghe T, D'Herde K, Vandenabeele P. Apoptosis and necrosis: detection, discrimination and phagocytosis. Methods 2008;44:205-21.

34. Keane RW, Kraydieh S, Lotocki G, Alonso OF, Aldana P, Dietrich WD. Apoptotic and antiapoptotic mechanisms after traumatic brain injury. J Cereb Blood Flow Metab 2001;21:1189-98.

35. Sango, K, Horie H, Saito H, Ajiki K, Tokashiki A, Takeshita K, Ishigatsubo $\mathrm{Y}$, Kawano $\mathrm{H}$, Ishikawa $\mathrm{Y}$. Diabetes is not a potent inducer of neuronal cell death in mouse sensory ganglia, but it enhances neurite regeneration in vitro. Life Sci 2002;71:2351-68.

36. Duchen LW, Scaravilli F. Quantitative and electron microscopic studies of sensory ganglion cells of the Sprawling mouse. J Neurocytol 1977;6:465-81.

37. Seylaz J, Hara H, Pinard E, Mraovitch S, MacKenzie ET, Edvinsson L. Effect of stimulation of the sphenopalatine ganglion on cortical blood flow in the rat. J Cereb Blood Flow Metab 1988;8:875-8.

38. Yasui T, Karita K, Izumi H, Tamai M. Correlation between vasodilatation and secretion in the lacrimal gland elicited by stimulation of the cornea and facial nerve root of the cat. Invest Ophthalmol Vis Sci 1997;38:2476-82.

39. Kaji A, Maeda T, Watanabe S. Parasympathetic innervation of cutaneous blood vessels examined by retrograde tracing in the rat lower lip. J Auton Nerv Syst 1991;32:153-8.

40. Yoon KC, Im SK, Seo MS. Changes of tear film and ocular surface in diabetes mellitus. Korean J Ophthalmol 2004;18:68-74.

41. Postorino M, Catalano C, Martorano C, Cutrupi S, Marino C, Cozzupoli P, Scudo P, Zoccali C. Salivary and lacrimal secretion is reduced in patients with ESRD. Am J Kidney Dis 2003;42:722-8.

42. Gibbins IL, Morris JL. Structure of peripheral synapses: autonomic ganglia. Cell Tissue Res 2006;326:205-26.

43. Hokfelt T, Elfvin LG, Elde R, Schultzberg M, Goldstein M, Luft R. Occurrence of somatostatin-like immunoreactivity in some peripheral sympathetic noradrenergic neurons. Proc Natl Acad Sci USA 1977;74:3587-91.

44. Gibbins IL. Vasomotor, pilomotor and secretomotor neurons distinguished by size and neuropeptide content in superior cervical ganglia of mice. J Auton Nerv Syst 1991;34:171-83.

45. Phillips LK, Rayner CK, Jones KL, Horowitz M. An update on autonomic neuropathy affecting the gastrointestinal tract. Curr Diab Rep 2006;6:417-23.

46. Ding C, He QP, Li PA. Diabetes increases expression of ICAM after a brief period of cerebral ischemia. J Neuroimmunol 2005;161:61-7.

47. Katz ML, Robison WG Jr. What is lipofuscin? Defining characteristics and differentiation from other autofluorescent lysosomal storage bodies. Arch Gerontol Geriatr 2002;34:169-84. 
48. Sugaya A, Sugimioto H, Mogi N, Tsujigami H, Deguchi S. Experimental diabetes accelerates accumulation of fluorescent pigments in rat trigeminal neurons. Brain Res 2004;999:132-4.

49. Schmidt RE, Plurad SB, Parvin CA, Roth KA. Effect of diabetes and aging on human sympathetic autonomic ganglia. Am J Pathol 1993; $143: 143-53$.

50. Ronco C, Grammaticopoulos S, Rosner M, De Cal M, Soni S, Lentini P, Piccini P. Oliguria, creatinine and other biomarkers of acute kidney injury. Contrib Nephrol 2010;164:118-27.

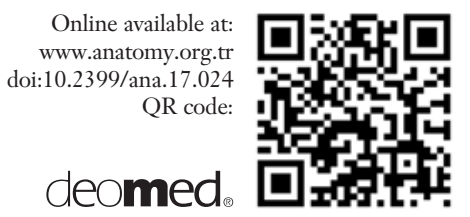

51. Sjöholm A, Nyström T. Inflammation and the etiology of type 2 diabetes. Diabetes Metab Res Rev 2006;22:4-10.

52. Danielle AT de Almeida, Camila PB,. Ethel LBN, Ana Angelica HF. Evaluation of lipid profile and oxidative stress in STZ-induced rats treated with antioxidant vitamin. Brazilian Archieves of Biology and Technology 2012;55:527-36.

53. Upchurch GR Jr, Keagy BA, Johnson G Jr. An acute phase reaction in diabetic patients with foot ulcers. Cardiovasc Surg 1997;5: $32-6$.

\author{
Correspondence to: Aijaz Ahmed Khan, MS, PhD \\ Department of Anatomy, Jawaharlal Nehru Medical College, \\ Aligarh Muslim University, Aligarh, U.P, India \\ Phone: +919897216343 \\ e-mail: aijazahmedkhan7@live.com \\ Conflict of interest statement: No conflicts declared.
}

This is an open access article distributed under the terms of the Creative Commons Attribution-NonCommercial-NoDerivs 3.0 Unported (CC BY-NCND3.0) Licence (http://creativecommons.org/licenses/by-nc-nd/3.0/) which permits unrestricted noncommercial use, distribution, and reproduction in any medium, provided the original work is properly cited. Please cite this article as: Faizal M, Khan AA. Effect of streptozotocin-induced diabetes on the autonomic ganglia of albino rats. Anatomy 2017;11(2):51-60. 